\title{
Anatomical patterns of cleft lip and palate deformities among neonates in Mekelle, Tigray, Ethiopia; implication of environmental impact
}

\author{
Konjit K. Bekele, Peter E. Ekanem *i] and Berhanu Meberate
}

\begin{abstract}
Background: Cleft lip and palate deformities are considered one of the most common birth defects of the head and neck that pose significant medical, psychosocial and financial burdens on the affected individuals and families, especially in low income communities. The etiology and pathogenesis of cleft lip and palate is complex and is known to involve genetic and/or environmental factors.

Objective: To assess the patterns of anatomical cleft lip and palate deformities among neonates in Mekelle and Ayder Comprehensive Specialized hospitals, Tigray, Northern Ethiopia.

Methods: A hospital-based retrospective study was conducted from May 2017 to June 2017 at Mekelle and Ayder Comprehensive Specialized hospitals, both in Mekelle city. Data was collected from all medical charts of neonates registered from 2011 to 2016 and analyzed using SPSS version 21.0 and OpenEpi software. Results were presented using tables and graphs; Chi-square test was used to look for an association between variables, odds ratio to determine the strength of association of selected variables using multinomial logistic regression model, while Fisher Exact (Clopper-Pearson) was used to compare yearly prevalence.

Results: Of 37,152 neonatal charts analyzed, 119 (0.32\%) cases were identified as having cleft deformities. 38.7, 17.6, and $43.7 \%$ of this figure had cleft lips, cleft palates and both cleft lip and palate respectively. 46 (38.7\%) neonates had lateral patterns of cleft lip deformities with $56.5 \%$ located unilaterally on the right and 43.5\% unilaterally on the left. Of 52 (43.7\%) neonates with cleft lip and palate deformities, $40.4 \%$ were located bilaterally while 38.5 and $21.2 \%$ were located unilaterally on the left and right, respectively. Associated malformations were: cardiac (3.4\%), central nervous system (1.7\%) and limb deformities (5.9\%). The overall prevalence of cleft deformities was found to be 3.11 per 1000 live births.

Conclusion: The study showed a higher prevalence of cleft deformities than that reported in Addis Ababa and some other African countries. A higher occurrence of left unilateral pattern of cleft lip and palate was observed whereas a higher right unilateral pattern of cleft lip was identified. The higher prevalence of cleft lip and palate recorded in this region of Ethiopia may reflect an environmental impact.
\end{abstract}

Keywords: Anatomical patterns, Cleft lips, Cleft palate, Neonates

\footnotetext{
* Correspondence: etimakpan@gmail.com

Department of Anatomy, College of Health Sciences, Mekelle University, P.O. Box 1674, Mekelle, Ethiopia
}

(c) The Author(s). 2019 Open Access This article is distributed under the terms of the Creative Commons Attribution 4.0 International License (http://creativecommons.org/licenses/by/4.0/), which permits unrestricted use, distribution, and reproduction in any medium, provided you give appropriate credit to the original author(s) and the source, provide a link to the Creative Commons license, and indicate if changes were made. The Creative Commons Public Domain Dedication waiver (http://creativecommons.org/publicdomain/zero/1.0/) applies to the data made available in this article, unless otherwise stated. 


\section{Background}

Birth defects are one of the leading causes of infant mortality in the world, contributing to more than 3 million deaths among children aged $<5$ years [1]. According to the World Health Organization (WHO) in 2010, an estimated 270,000 neonatal deaths globally were attributable to congenital anomalies. Congenital malformations of the head and neck with cleft lip and palate anomalies (CLP) are considered the most common forms of birth defects. CLP are derived embryologically, from defects in the primary fusion of the craniofacial processes that form the primary and secondary palate between the 5th and 12th weeks of development. Based on the anatomy of the incisive foramen as a landmark, CLP are classified into: pre-incisive foramen or clefts lip (CL), post-incisive foramen or cleft palate $(\mathrm{CP})$, trans-incisive foramen or cleft lip and palate (CL/P) [2]. CLP are also designated clinically by their location and descriptive terms, such as unilateral, bilateral, or midline and complete, incomplete, or sub-mucus. [3] Clefts occur in 2 groups: syndromic or isolated. Syndromic clefts are typically accompanied by abnormalities in other developmental fields or organ systems e.g., limbs, central nervous system (CNS), cardiovascular system (CVS), etc.

Structurally, CL results from a lack of fusion of maxillary and nasomedial processes. The mechanism frequently underlying CL is hypoplasia of the maxillary process that prevents contact between the maxillary and nasomedial processes. It may also result from deficiency in the merging of several mesenchymal masses and proliferations to smoothen out the overlying epithelium. Cleft palate, on the other hand results from incomplete or absence of fusion of the palatal shelves [4].

Etiology and pathogenesis of CLP are poorly understood and compass both genetic and environmental factors. Genetic factors associated with CLP have been identified in several research works and include: TGF- $\beta 3$ (Transforming growth factor beta 3), MSX1 (Msh homeobox1), IRF-6 (Interferon regulatory factor- 6), FGFs (Fibroblast growth factor), PVRL1 (Poliovirus receptor related-1), FOXE1 (Forkhead box E1), JAG2 (Jagged 2) and TBX22 (T-box22) [2]. Environmental factors such as mother's diet, vitamin supplementation, and use of alcohol, smoking, and anticonvulsant drugs have been implicated in the development and high incidence of CLP. CLP generally have an aesthetic significance and impact which pose significant medical, psychosocial and financial challenges on both the patients and caregivers $[1,3]$. The complications associated with CLP include feeding difficulties which appear after birth due to anatomical defective structures impairing suckling and swallowing. Others are: scarring, dental problems, speech and hearing impairments, deficient maxillofacial growth and aesthetic challenges, which may attract bullying among peers and segregation. These factors consequently lead to low self-esteem and low quality of life indices [5].

Global prevalence of cleft lip and palate deformities ranges from 2.7 to 9.92 cases per 1,000 live births [6] with variability by country, race, geographical location, gender and ethnic group. The lowest reported incidence is among African-American populations (approximately 0.5 per 1 , 000) $[7,8]$ while a higher incidence exists among native Americans (approximately 3.5 per 1,000) [9-12].

Although a number of research studies have been carried out to determine the prevalence of CLP in several African countries including Ethiopia (Addis Ababa), none has been conducted in Mekelle (a city in Northern Ethiopia), where a large number of orofacial defects has been seen. This has prompted this study aimed at assessing the patterns and prevalence of CLP among neonates born in or attending $\mathrm{ACSH}$ and $\mathrm{MH}$, Mekelle, for the purpose of devising correct surgical interventions and prevention of these defects.

\section{Methods}

The present study was conducted in two main government hospitals: $\mathrm{MH}$ and ACSH in Tigray regional state of Northern Ethiopia from May 2017 to June 2017. $\mathrm{ACSH}$ is the second largest hospital in Ethiopia, serving a catchment population of over 8 million people from Tigray, Afar and the Southeastern part of Amhara states. $\mathrm{MH}$ serves over 2 million people mainly from Tigray state. A retrospective study with purposive sampling technique was employed. The study population included all neonates with cleft lip and palate deformities registered from 2011 to 2016. All affected neonates with complete chart documentation were included while those with missing pertinent data were excluded.

An adapted structured checklist was used to extract data from delivery registration books and medical records. Variables studied were cleft deformities and associated anomalies like congenital heart defects, central nervous system (CNS) and extremity malformations as they relate to patients' sex. 37,152 birth and attendance records from 2011 to 2016 were retrieved. The data collected were analyzed using SPSS ${ }^{\mathrm{Tm}}$ software (version 21.0) and Open $\mathrm{Epi}^{\mathrm{im}}$. For descriptive purposes, results were presented as frequency and percentages in tables and graphs. Fisher Exact (Clopper-Pearson) compared the yearly prevalence, Chi-square tested association between variables while Odds ratio was used to determine the strength of association of selected variables using multinomial logistic regression model. $P<0.05$ was considered statistically significant.

Ethical clearance was obtained from the Ethical Review Board of Mekelle University, College of Health Sciences and an official letter of support was sent to ACSH and 


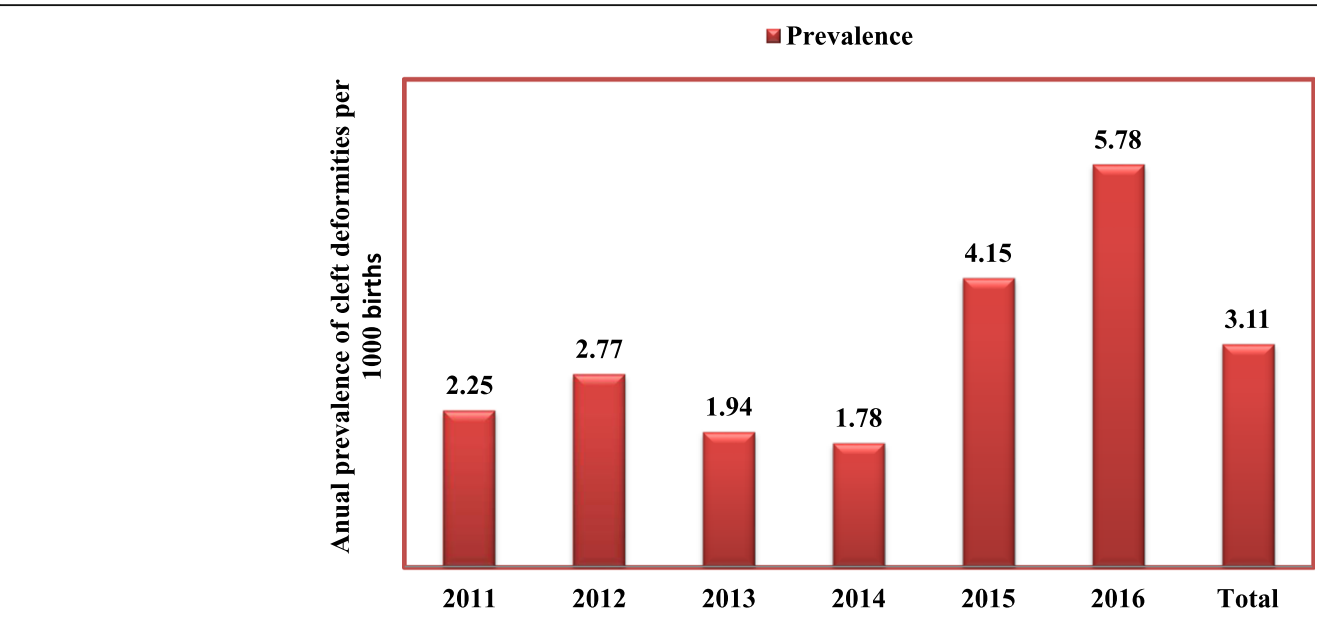

Fig. 1 The prevalence of CLP among the neonates delivered in ACSH and MH in 2011-2016. (The prevalence was: in 2011, 0.23 [Cl: (0.06-0.72)]; in 2012, 0.28 [Cl: (0.06-0.72)]; 2013, 0.19 [Cl: (0.02-0.56)]; 2014, 0.18 [Cl: (0.02-0.56)]; 2015, 0.42 [Cl: (0.16-1.02)]; 2016, 0.58 [Cl: (0.22-1.16))

MH. Confidentiality was maintained throughout the study process.

\section{Results}

In total, there were 37,152 registered neonates during 2011-2016 at ACSH and MH, and 119 (0.32\%) of neonates were identified with orofacial clefting $(\mathrm{CL}, \mathrm{CP}$ and $\mathrm{CL} / \mathrm{P})$. The overall prevalence from these two facilities from 2011 to 2016 was 3.11 per 1000 live births.

\section{Discussion}

The prevalence of orofacial clefts differs among different populations. In the present study, distribution of oral clefts was seen in $0.32 \%$ of 37,152 registered neonates between 2011 and 2016 at ACSH and MH (Fig. 1). The overall prevalence was 3.11 per 1,000 live births indicating a higher figure compared to those obtained in Caucasian populations (approximately 1 per 1000 births) and Asian populations (approximately 1.7 per 1000 births) [10, 13]. Nigerian literature reviewed revealed that the prevalence of cleft anomalies was approximately $0.37 / 1,000$ live births, a Ugandan study reported 1.45/1, 000 live births, Tunisia, 1.40/1,000 live births and South Africa, 0.3/1000 live births [14-17]. In an earlier study conducted at Addis Ababa Ethio-Swedish children's hospital, $8 \%$ of children under study were treated for cleft deformities [18] and prevalence of CLP was approximately 1.49/1,000 live births [5]. Contributing discrepancy between the findings in Addis Ababa as a cosmopolitan city and Mekelle may be due to heterogeneous population in Addis Ababa, differences in time period, socio-economic status, sample size and study design. The lower regional prevalence of CLP in Addis Ababa may also be associated with improved living conditions hence reducing the risk of developing CLP. The data in our study indicated a surge in the prevalence recorded in 2015 and 2016 compared with previous years (Fig. 1). Analysis of this prevalence did not reveal any

\section{Types of Cleft Deformities}

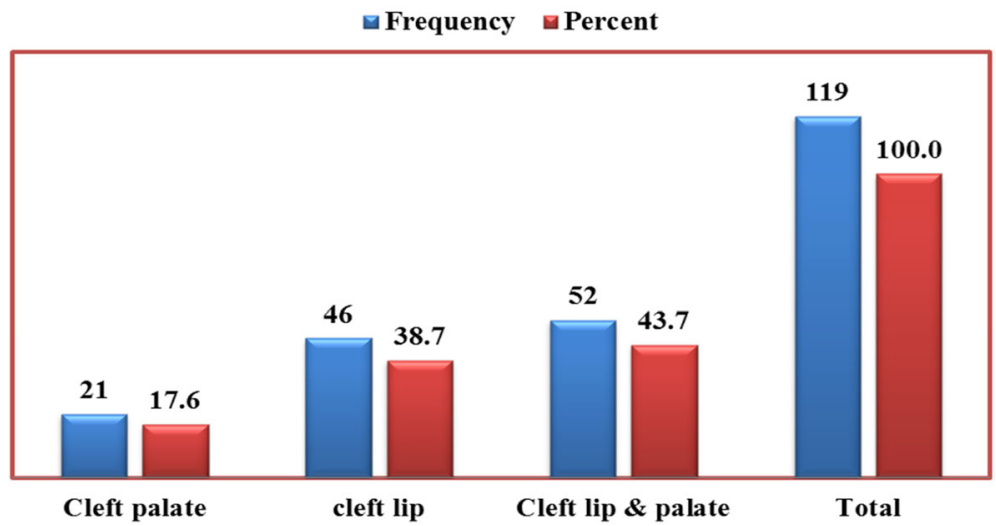

Fig. 2 Types of cleft among neonates in ACSH and MH in 2011-2016 
Table 1 Frequency of cleft deformities among neonates in ACSH and $\mathrm{MH}$ based on sex and cleft deformity types

\begin{tabular}{lllll}
\hline \multirow{2}{*}{$\begin{array}{llll}\text { Characteristics } \\
N=119)\end{array}$} & Category & \multicolumn{2}{l}{ Sex of live births } & Total \\
\cline { 3 - 4 } & & Male & Female & \\
\hline Type of Cleft lip & Cleft lip & $21(17.6 \%)$ & $25(21 \%)$ & $46(38.7 \%)$ \\
& Cleft palate & $14(11.8 \%)$ & $7(5.9 \%)$ & $21(17.6 \%)$ \\
& Cleft lip and & $28(23.5 \%)$ & $24(20.2 \%)$ & $52(43.7 \%)$ \\
palate & & & \\
Total & & $63(52.9 \%)$. & $56(47.1 \%)$ & $119(100 \%)$ \\
\hline
\end{tabular}

significant difference from the previous years. We conclude that the surge may have resulted from increased use and attendance at both facilities occasioned by societal education and improved healthcare services introduced at these hospitals to guarantee safe delivery and patient care.

We found that of the 119 cases of clefting, 43.7\% had CL/P, 38.7\% had CL and 17.6\% CP deformities, signifying a higher frequency of $\mathrm{CL} / \mathrm{P}$ deformities than $\mathrm{CL}$ and $\mathrm{CP}$ (Fig. 2). In Addis Ababa, a higher incidence of $\mathrm{CL} / \mathrm{P}$ than $\mathrm{CL}$ and $\mathrm{CP}$ was recorded [5]. Other studies conducted in South Indian population showed similar results, indicating $\mathrm{CL} / \mathrm{P}$ being the most frequently occurring cleft anomaly, thus corroborating our result [19-21]. A contrasting view has been promulgated by Khajanchi et al. who asserted in their work that occurrence of CL was the most common cleft abnormality followed by CL/P [22]. Environmental factors have been associated with increased risk of $\mathrm{CL} / \mathrm{P}$ including: consanguinity, smoking, alcohol ingestion, use of anticonvulsants during pregnancy as well as insufficient folic acid intake in the pregestational period and first trimester of pregnancy [23]. Mekelle city is fast evolving as the commercial hub of the northern part of Ethiopia with high rate of smoking, alcohol use and other forms of social indulgences. These factors may precipitate a high rate of $\mathrm{CL} / \mathrm{P}$ found in Mekelle as in other commercial capitals of the world.
In this study, cleft deformities were found to be more common in males $(52.9 \%)$ than females (47.1\%) Table 1. Similar findings were described in Addis Ababa and among four provinces in West and Northwest Iran $[5,24]$. The male: female ratio for CL, CP and CL/P in our study was 1:1.19, 1:0.5 and 1:0.86, respectively, revealing a higher occurrence of $\mathrm{CP}$ and $\mathrm{CL} / \mathrm{P}$ among males than females while the female to male ratio in $\mathrm{CL}$ was higher. In contrast, more females were reported to have $\mathrm{CP}$ than males in Addis Ababa [5, 18] and Lahore, Pakistan [25]. A higher prevalence of milder CP was found in males as opposed to more severe forms in which females were more prevalent in a Japanese study [26]. The higher prevalence of $\mathrm{CP}$ in males found in our study may also be associated with occurrence of milder forms of the anomaly though this was not evaluated.

$56.5 \%$ of cleft lip deformities in this study were found unilaterally on the right side while $43.5 \%$ were located on the left (Fig. 3). Our result here is divergent to widely reported higher left sided unilateral clefts than rightsided CLs [27-29]. Majority (40.4\%) of CL/P were located bilaterally. Unilateral patterns had a left sided dominance (38.5\%) while right sided was $21.2 \%$ (Table 2). This finding is validated by the results obtained in Addis Ababa where $40.5 \%$ of CL/P were located bilaterally, $33.3 \%$ unilaterally on the left side and $27.8 \%$ unilaterally on the right. Other authors have, however, reported higher occurrences of left unilateral $\mathrm{CL} / \mathrm{P}$ than right sided and bilaterally $[5,30,31]$.

$11.0 \%$ of neonates with CLP had associated congenital anomalies (Table 3). Limb malformations were most commonly seen at $5.9 \%$ followed by congenital heart defects $(3.4 \%)$ and CNS malformations (1.7\%). Associated malformations of CLP were recorded in other countries like Jordan [32]. In Addis Ababa, 14.1\% of CLP patients had associated congenital anomalies with 7.8, 4.8 and $1.6 \%$ limb, CNS and cardiac malformations respectively [5]. In contrast, an Iranian study had 13\% of CLP neonates associated with other congenital anomalies of the

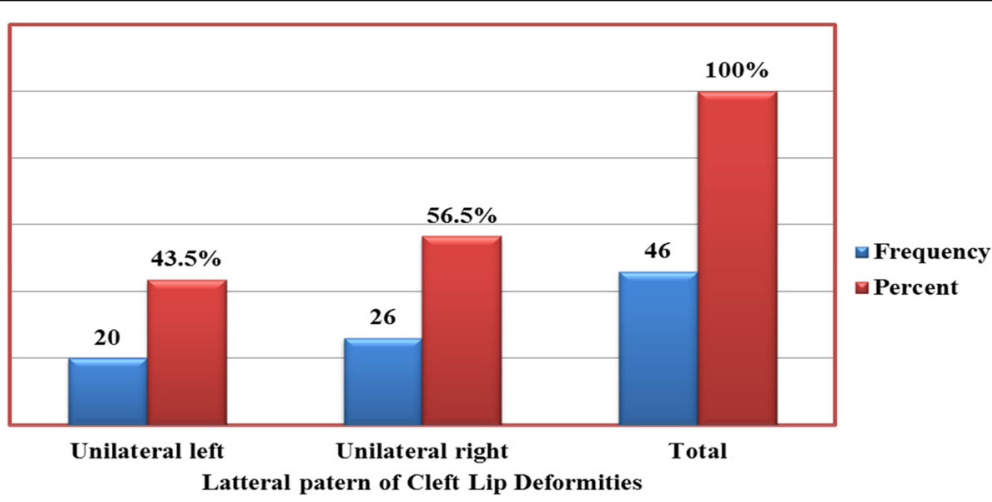

Fig. 3 Lateral patterns of cleft lip deformities 
Table 2 Lateral patterns of CLP deformities among neonates in $\mathrm{MH}$ and $\mathrm{ACSH}, 2011-2016$

\begin{tabular}{lll}
\hline & Category & Number (\%) \\
\hline Lateral pattern of cleft lip & Unilateral Right & $11(21.15 \%)$ \\
and palate deformities & Unilateral Left & $20(38.46 \%)$ \\
& Bilateral & $21(40.38 \%)$ \\
Total & & $52(100 \%)$ \\
\hline
\end{tabular}

head, face and heart [33]. The higher incidence of limb malformations may be due to their association with neural tube defects, whose prevalence has been found to be as high as 26 times the normal non-folic acid preventable rate in Tigray region, Northern Ethiopia [34].

In this study we tried to associate patients' sex with the occurrence of cleft lip and palate deformities. Our analysis did not show any statistically significant association as shown in Table 4. Martelli et al. found in their work that there were significant differences in the distribution of non-syndromic cleft lip and/or palate between males and females; $\mathrm{CP}$ were frequent in females while CLP predominated in males [35]. Association between cleft lip severity and sex was found in the study conducted by Carroll and Mossey, with females having a significantly greater proportion of $\mathrm{CL}$ and $\mathrm{CL} / \mathrm{P}$ in males [36].

Environmental factors in Tigray region of Ethiopia may have a strong correlation with the development of clefting. This is because folic acid, which is found in green vegetables and fruits, is one of the vital nutrients that have been found deficient among Ethiopian women [37]. Catechins, found in tea consumed generally by the people of this region several times a day, also inhibit intestinal folate absorption. When consumed by women in the periconceptional period as is commonly found in this region it may predispose them further to folate deficiency and CLP [38]. The influence of environmental factors on the incidence of CLP has been elucidated by experiments conducted in mice, which showed that the likelihood of occurrence of $\mathrm{CP}$ after exposure to a dose of cortisone strongly correlated to the genetic background

Table 3 Associated congenital malformations among neonates with cleft lip and palate deformities based on sex at $\mathrm{MH}$ and ACSH, 2011-2016

\begin{tabular}{lllll}
\hline Characteristics & Category & \multicolumn{2}{l}{ Sex of neonate } & Total \\
\cline { 3 - 4 } & & Male & Female & \\
\hline $\begin{array}{l}\text { Live births } \\
\text { malformation }\end{array}$ & $\begin{array}{l}\text { Congenital heart } \\
\text { defect }(N=4) \\
\end{array}$ & $1(25 \%)$ & $3(75 \%)$ & $4(100 \%)$ \\
& $\begin{array}{l}\text { Central nervous } \\
\text { malformation }(N=2)\end{array}$ & $2(100 \%)$ & $0(0 \%)$ & $2(100 \%)$ \\
& $\begin{array}{l}\text { Extremity malformation } \\
(N=7)\end{array}$ & $5(71.4 \%)$ & $2(28.6 \%)$ & $7(100 \%)$ \\
Total & & 8 & 5 & 13 \\
\hline
\end{tabular}

Table 4 Association between sex and CLP

\begin{tabular}{|c|c|c|c|c|c|}
\hline \multirow{2}{*}{$\begin{array}{l}\text { Characteristics } \\
(n=119)\end{array}$} & \multirow[t]{2}{*}{ Categories } & \multicolumn{2}{|c|}{ Sex of neonates } & \multirow[t]{2}{*}{ COR $(95 \% \mathrm{Cl})$} & \multirow{2}{*}{$\begin{array}{l}P \text { - } \\
\text { Value }\end{array}$} \\
\hline & & $\overline{\text { Male }}$ & $\overline{\text { Female }}$ & & \\
\hline \multirow{3}{*}{$\begin{array}{l}\text { Types of cleft } \\
\text { deformities }\end{array}$} & Cleft lip & 21 & 25 & $0.72(0.32-1.59)$ & 0.42 \\
\hline & Cleft palate & 14 & 7 & $1.71(0.59-4.94)$ & 0.32 \\
\hline & Cleft lip \& palate & 28 & 24 & $1.00^{+}$ & $1.00^{+}$ \\
\hline
\end{tabular}

When sex was associated with cleft lip and palate deformities using multinomial logistic regression analysis, it was not found to be significant $(p>0.05)$ $1.00^{+}=$Reference

of the mice. In humans, mutations of MSX1 gene are strongly associated with non-syndromic cleft palate [4]. Biological activities linked to orofacial pathology in certain genes but without direct involvement have been identified in folic acid receptor 1 (FOLR1). Susan et al. demonstrated through their research that perturbations of the genes in the folate pathway might contribute to the development of non-syndromic cleft lip with or without cleft palate (NSCLP) [39]. It has been shown that folate supplementation to women during the periconceptional period reduced the incidence of CL/ $\mathrm{P}$ substantially as compared to that in the non-supplemented controls [40].

Therefore, these environmental factors highlighted may have a significant role in the high prevalence of CLP in Mekelle and Tigray region of Ethiopia.

\section{Conclusions}

The overall prevalence of cleft deformities observed in $\mathrm{ACSH}$ and $\mathrm{MH}$, reflective of their catchment populations, was relatively higher than what other studies have reported. A higher occurrence of clefting was observed in males than females. The influence of environmental factors and nutrition may have contributed to the high incidence.

Periconceptional administration of folate in this region as a policy may help alleviate the problems associated with orofacial development significantly.

The scope of the present study was limited to the two health facilities in Mekelle, Tigray region of Ethiopia. Acquisition of pertinent maternal history, which may have been useful to broaden the study variables and strengths of association, was also limited by insufficient data. These may explain some of the variations in this work when compared with other studies.

\section{Abbreviations \\ ACSH: Ayder Comprehensive Specialized Referral Hospital; CL: Cleft lip; CL/ P: Cleft lip and palate; CLP: Cleft lip and palate deformities; CNS: Central Nervous System; CP: Cleft palate; MH: Mekelle Hospital; NSCLP: Non syndromic cleft lip and palate}

\section{Acknowledgments}

The authors would like to acknowledge Dr. A.C. Kendi Nyaga for typesetting and providing useful advice and Mr. Girum Taye for assisting in data analysis; Mekelle University and the members of Human Anatomy Department, Ayder 
Comprehensive Specialized and Mekelle hospitals' staff for their assistance and cooperation as well as for allowing us to do our research in their labor wards and neonatal intensive care units.

\section{Authors' contributions}

K.K.B: Conceptualized and designed the study, collected data and approved final manuscript publication. P.E.E.: Conceptualized and designed the study, drafted and revised the article and approved final manuscript publication. B.M.: Advised on the process of data collection and approved final manuscript publication.

\section{Funding}

The study was funded by Mekelle University who offered financial support following their approval of the research topic, study methods, data collection, interpretation and analysis. They also encouraged the writing of the manuscript for the purpose of dissemination of these findings.

\section{Availability of data and materials}

Datasets generated and analyzed in this work can be found both in Mekelle and Ayder Comprehensive Referral Hospitals. Restrictions apply to the availability of the data for confidentiality purposes, and are thus not publically available. Data are however available upon reasonable request with permission from the respective hospitals.

\section{Ethics approval and consent to participate}

Ethical clearance was obtained from the Ethical Review Board of Mekelle University, College of Health Sciences, and an official letter of support was sent to $\mathrm{ACSH}$ and $\mathrm{MH}$.

\section{Consent for publication}

Not applicable.

\section{Competing interests}

The authors declare that they have no competing interests.

Received: 28 September 2018 Accepted: 12 July 2019

Published online: 24 July 2019

\section{References}

1. Kancherla V, Oakley GP Jr, Brent RL. Urgent global opportunities to prevent birth defects, Semin Fetal Neonatal Med. (2013) 1-8.

2. Sibele NA, Lívia MRP, Daniella RBM, Mário Sérgio OS, Letízia MB, Paulo RF, Hercilio MJ. Study of patients with cleft lip and palate in consanguineous parents. Braz J Otorhinolaryngol. 2011;77(1):19-23.

3. Abbot MA. Cleft lip and palate. Pediatr Rev. 2014;35(5):177-80.

4. Carlson, BM. Human Embryology \& developmental Biology, 5th ed, 2014 Elsevier, Philadelphia.

5. Eshete M, Gravenm PE, Topstad T, Befikadu S. The incidence of cleft lip and palate in Addis Ababa. Ethiopia Ethiop Med J. 2011;49:1-5.

6. Dvivedi JS. A clinical and demographic profile of the cleft lip and palate in sub-Himalayan India: a hospital-based study. Indian J Plast Surg. 2012;45(1) $115-20$.

7. Mossey PA, Little J, Munger RG, Dixon MJ, Shaw WC. Cleft lip and palate. Lancet. 2009;374:1773-85.

8. Croen LA, Shaw GM, Wasserman CR, Tolarová MM. Racial and ethnic variations in the prevalence of orofacial clefts in California, 1983-1992. Am J Med Genet. 1998;79:42-7.

9. Niswander JD, Barrow MV, Bingle GJ. Congenital Malformations in the American Indian. Social Biology 2010 [cited 18 Sept 2018];22(3):203-215: Available from https://doi.org/10.1080/19485565.1975.9988168

10. Ireland $\mathrm{CL}$ and PA. The incidence of clefts [Internet]. Cleft Lip and Palate Association of Ireland website. 2017. Available from: http://www.cleft.ie/ ?page_id=25. [cited 3 Aug 2018].

11. Young G, Deskin FR, Editor S, Quinn FB. Cleft Lip and Palate : UTMB Dept of Otolaryngology Grand Rounds 2011; 1-5.

12. Mulliken JB. Repair of bilateral complete cleft lip and nasal deformity - state of the art. Cleft Palate-Craniofacial J. 2000;37:342-7.

13. Vanderas AP. Incidence of cleft lip, cleft palate, and cleft lip and palate among races: a review. Cleft Palate-Craniofacial J. 1987;24:216-25.

14. Iregbulem LM. The incidence of cleft lip and palate in Nigeria. Cleft PalateCraniofacial J. 1982;19:201-5.
15. Tungotyo M, Atwine D, Nanjebe D, Hodges A, Situma M. The prevalence and factors associated with malnutrition among infants with cleft palate and/or lip at a hospital in Uganda: a cross-sectional study. BMC Pediatr. 2017;17:17.

16. Khrouf N, Spang R, Podgorna T, Miled SB, Moussaoui M, Chibani M. Malformations in 10000 consecutive births in Tunis. Acta Paediatr. 1986; 75:534-9.

17. Hlongwa P, Levin J, Rispel LC. Epidemiology and clinical profile of individuals with cleft lip and palate utilising specialised academic treatment centres in South Africa. PLoS ONE. 2019;14(5):e0215931.

18. Daniel E, Melaku G, Yoo MC, Agzew Y, Gebre W. Analysis of surgical admissions to the Ethio-Swedish Children's hospital (1984-1988) in Addis Ababa. Ethiop Med J. 1990;28:15-22.

19. Rajeev BR, Prasad K, Shetty PJ, Preet R. The relationship between orofacial clefts and consanguineous marriages: A hospital register-based study in South India. J Cleft Lip Palate Craniofac Anomal 2017:4:3-8

20. Murthy J, Venkatesh Babu G, Bhaskar L. Clinical and demographic factors associated with cleft lip and palate in South India: a hospital based study. Int J Latest Res Sci Technol. 2004;3:803.

21. Reddy SG, Reddy RR, Bronkhorst EM, Prasad R, Ettema AM, Sailer HF, et al. Incidence of cleft lip and palate in the state of Andhra Pradesh, South India. Indian J Plast Surg. 2010:43:184-9.

22. Khajanchi MU, Shah H, Thakkar P, Gerdin M, Roy N. Unmet burden of cleft lip and palate in rural Gujarat. India: A population- based study World J Surg. 2015;39:416

23. Desai BB, Patel DP, Sinha SV, Jain M, Patel RN, Bhanat ST. Correlating causative factors in cleft lip and palate patients: an epidemiological study. J Cleft Lip Palate Craniofac Anomal. 2019;6:11-6.

24. Nahid J, Shohreh J. Prevalence of cleft lip and palate among four provinces in the west and north-west of Iran. J Res Med Sci. 2015;20: 548-53.

25. Yaqoob M, Mahmod F, Harif G, Bugvi SM, Sheikh MA. Etiology and genetic factors in cleft of lip and /or palate reported at Children's hospital, Lahore, Pakistan Indian. J Hum Genet. 2013;19:136-43.

26. Nagase $Y$, Natsume N, Kato T. Hayakawa Toko. Epidemiological analysis of cleft lip and/or palate by cleft pattern. J Maxillofac Oral Surg. 2010; 9(4):389-95.

27. Daskalogiannakis J, Kuntz KL, Chudley AE, Ross RB. Unilateral cleft lip with or without cleft palate and handedness: is there an association? Cleft Palate Craniofac J. 1998;35(1):46-51.

28. Murthy J, Bhaskar L. Current concepts in genetics of nonsyndromic clefts. Indian J Plast Surg. 2009;42:68-81.

29. Jamilian A, Lucchese A, Darnahal A, Kamali Z, Perillo L. Cleft sidedness and congenitally missing teeth in patients with cleft lip and palate patients. Prog Orthod. 2016;17:14

30. Jamilian A, Nayeri F, Babayan A. Incidence of cleft lip and palate in Tehran. J Indian Soc Pedod Pev Dent. 2007;25:174-6.

31. Gonzalez BS, Lopez ML, Rico MA, Garduno F. Oral clefts: retrospective study of prevalence and predisposal factors in the state of Mexico. J Oral Sci. 2008:50:123-9.

32. Al Omari F, Al-Omari IK. Cleft lip and palate in Jordan: birth prevalence rate. Cleft Palate-Craniofacial J. 2004:41:609-12.

33. Yazdee AK, Saedi B, Sazegar AA, Mehdipour P. Epidemiological aspects of cleft lip and palate in Iran. Acta Med Iran. 2011:49:54-8.

34. Berihu BA, Welderufael AL, Berhe Y, Magana T, Mulugeta A, Asfaw S, et al. High burden of neural tube defects in Tigray. Northern Ethiopia: Hospitalbased study PLOS One. 2018;13(11):e0206212.

35. Martelli DRB, Cruz KW, Barros LM, Silveira MF, Swerts MSO. Martelli- Júnior H. maternal and paternal age, birth order and interpregnancy interval evaluation for cleft lip-palate. Braz J Otorhinolaryngol. 2010;76(1):107-12.

36. Carroll K, Mossey PA. Anatomical variations in clefts of the lip with or without cleft palate. Plast Surg Int. 2012;2012:6. https://doi.org/10.1155/2 012/542078.

37. Sorri G, Mesfin E. Patterns of neural tube defects at teaching hospitals in Addis Ababa, Ethiopia: a three years retrospective study. Ethiop Med J. 2015; 53(3):119-26.

38. Yazdy MM, Tinker SC, Mitchell AA, Demmer LA, Werler MM. Maternal tea consumption during early pregnancy and the risk of spina bifida. Birth Defects Res A Clin Mol Teratol. 2012:94(10):756-61.

39. Susan HB, Robin RH, Quiping Y, John BM, Samuel S, Richard HF, Jacqueline $\mathrm{TH}$. The folate pathway and nonsyndromic cleft lip and palate. Birth Defects Res A Clin Mol Teratol. 2011;91(1):50-60. 
40. Haidar J, Melaku U, Poboei KSS. Folate deficiency in women of reproductive age in nine administrative regions of Ethiopia: an emerging public health problem. Afr J Clin Nutr. 2010;23(3):132-7.

\section{Publisher's Note}

Springer Nature remains neutral with regard to jurisdictional claims in published maps and institutional affiliations.

Ready to submit your research? Choose BMC and benefit from:

- fast, convenient online submission

- thorough peer review by experienced researchers in your field

- rapid publication on acceptance

- support for research data, including large and complex data types

- gold Open Access which fosters wider collaboration and increased citations

- maximum visibility for your research: over $100 \mathrm{M}$ website views per year

At $\mathrm{BMC}$, research is always in progress. 